\title{
Artigo Original / Original Paper \\ Biologia reprodutiva e polinização de Palicourea crocea (Rubiaceae), uma espécie distílica e ornitófila no Cerrado de Goiás, Brasil
}

\author{
Reproductive biology and pollination of Palicourea crocea (Rubiaceae), \\ the distylous and ornithophilous specie in the Cerrado of Goiás, Brazil
}

\author{
Christiano Peres Coelho ${ }^{1,4,5}$, Hélder Nagai Consolaro ${ }^{2}$ \& Paulo Eugênio Oliveira ${ }^{3}$
}

\begin{abstract}
Resumo
A heterostilia é um polimorfismo floral geneticamente controlado onde populações de plantas apresentam dois ou três morfos com peças reprodutivas em alturas recíprocas entre os morfos. Em populações naturais, espera-se encontrar uma razão igual entre os morfos (isopletia). O objetivo do estudo foi caracterizar o sistema reprodutivo, a biologia floral, as características heterostílicas, incluindo reciprocidade das peças reprodutivas, fenologia e polinização em Palicourea crocea, uma espécie arbustiva do sub bosque de formações florestais do Cerrado. Para tal foram medidas estruturas florais, realizados cruzamentos controlados, observados os visitantes florais, além de acompanhamento fenológico. Palicourea crocea é uma espécie distílica típica, autoincompatível, com altos índices de hercogamia recíproca entre os morfos. Polinizada preferencialmente por beija-flores, além de mariposas e abelhas. Houve formação maior de frutos em polinização cruzada intermorfo $(>50 \%)$ e menor formação em polinização intramorfo $(<20 \%)$ e autopolinização $(<13 \%)$. Esses dados foram confirmados pelo não crescimento de tubos polínicos em pistilos autopolinizados e polinizados de forma intramorfo. A floração é anual, e ocorre entre os meses de novembro e fevereiro, com pico de floração em dezembro e janeiro. Os dados reprodutivos avaliados se mostram similares a outras espécies de Rubiaceae do sub bosque de ambientes florestais do Cerrado.
\end{abstract}

Palavras-chave: beija-flores, Cerrado, Rubiaceae, heterostilia.

\begin{abstract}
The heterostyly is a floral polimorphysm genetically controlled where populations of plants present two or three morphs with reproductive structures in reciprocal heights among the morphs. In natural populations, a balanced ratio between morphs (isoplethy) is expected. The objective of the study was to characterize the breeding system, the floral biology, the characteristics of heterostyly, including reciprocity of reproductive parts, the phenology and pollination in Palicourea crocea, a shrub species of the understory of forest formations of Cerrado. For such measures were floral structures, held controlled crossings, observed flower visitors, in addition to phenological monitoring. Palicourea crocea is proved to be a typical distylous species, self-incompatible, with high levels of reciprocal herkogamy between the morphs. Preferentially pollinated by hummingbirds, followed by moths and bees. There was a higher fruit formation in cross-pollination intermorph $(>50 \%)$ and lower fruit formation intramorph pollination $(<20 \%)$, and self-pollination $(<13 \%)$. These data were confirmed by the not growth of pollen tubes in self-pollination and pollinated intramorph pistils. Flowering is annual and occurs between the months of November and February, with peak flowering in December and January. Reproductive data evaluated to show similar to other species of Rubiaceae of the understory of forest formations of Cerrado.
\end{abstract}

Key words: hummingbirds, Cerrado, Rubiaceae, heterostyly.

\footnotetext{
${ }^{1}$ Universidade Federal de Jataí, Unidade Acadêmica Especial de Ciências Biológicas, Herbário Jataiense, Rod. BR-364, km 195, 3800, 75801-615, Jataí, GO, Brasil.

${ }^{2}$ Universidade Federal de Catalão, Depto. Ciências Biológicas, Av. Lamartine Pinto de Avelar 1120, Setor Universitário, 75704-020, Catalão, GO, Brasil.

${ }^{3}$ Universidade Federal de Uberlândia, Inst. Biologia, Av. Pará 1720, Campus Umuarama, 38405-320, Uberlândia, MG, Brasil.

${ }^{4}$ ORCID: <https://orcid.org/0000-0001-7631-3140>

${ }^{5}$ Autor para correspondência: cpcbio@hotmail.com
} 


\section{Introdução}

Uma das estratégias que trouxe muitas vantagens ao sucesso reprodutivo das plantas foi o hermafroditismo, mas esta característica não está isenta de desvantagens (Rech et al. 2014). Isto porque as plantas podem apresentar conflitos de interesse entre os órgãos sexuais, produzindo dessa forma interferência entre as peças sexuais quando estas compartilham espaço e tempo (Barrett 2000), visto que as anteras querem a doação de pólen para outras flores, se possível de outros indivíduos, enquanto o estigma quer o recebimento de pólen também de outros indivíduos. A coexistência no tempo e espaço acaba afetando negativamente a busca por um fluxo polínico entre indivíduos distintos, gerando a autopolinização. Uma forma de reduzir ou evitar o conflito de interesses, são alterações morfológicas e fisiológicas na estrutura floral, como é o caso da hercogamia - separação espacial entre os órgãos reprodutivos (Webb \& Lloyd 1986) ou a dicogamia - separação temporal entre a maturação dos órgãos reprodutivos (Lloyd \& Webb 1986). Estas estratégias são muito úteis, mas não são totalmente seguras para evitar a autopolinização ou a geitonogamia. Estratégias fisiológicas, como sistemas de incompatibilidade, surgem então, para permitir que as estruturas sexuais estejam na mesma estrutura floral, mas que mantenham o sucesso reprodutivo (Pérez-Barrales 2005).

Entre estas estratégias está a heterostilia, um polimorfismo floral geneticamente controlado, que apresenta populações com dois morfos (distilia) ou com três morfos (tristilia), com diferenças recíprocas no comprimento do estilete e das anteras, e associado com um sistema de autoincompatibilidade dialélico esporofítico, onde somente cruzamentos entre os morfos opostos geram sementes férteis (Ganders 1979). Variações de incompatibilidade em espécies distílicas pode ser resultado do relaxamento ou da perda da incompatibilidade (Barrett \& Richards 1990; Lloyd \& Webb 1990), muitas vezes relacionados com a quebra da heterostilia e o surgimento de formas variantes (Barrett \& Shore 2008), como a homostilia (Coelho \& Barbosa 2003).

Darwin (1877) sugeriu que a heterostilia é um importante mecanismo para promover cruzamento entre indivíduos distintos, devido o pólen de um morfo ser mais provavelmente depositado em uma parte do corpo do visitante, que vai tocar o estigma da forma oposta, realizando assim "polinização legítima”, uma hipótese parcialmente confirmada por estudos posteriores (Sobrevila et al. 1983; Ree 1997; Weller 2009; Barrett 2010; Valois-Cuesta et al. 2012; Bramow et al. 2012; Faria \& Araújo 2016; Matias et al. 2016).

A distilia, o tipo mais comum de heterostilia, ocorre em 23 famílias de angiospermas (Ree 1997; Weller 2009). É um sistema reprodutivo de plantas em que estiletes longos e curtos ocorrem em frequências aproximadamente iguais em populações naturais. Os morfos florais diferem na altura dos estames e estigmas e tem uma reciprocidade entre as peças reprodutivas que apresentam auto e intra morfo incompatibilidade. Outros dimorfismos acessórios podem ser identificados, como tamanho e produção de grãos de pólen (Dulberger 1992), tamanho da flor, tamanho do estigma, tamanho das papilas estigmáticas, etc. (Vuilleumier 1967).

O gênero Palicourea Aubl. pertence à tribo Psychotrieae da família Rubiaceae e está sendo relatado como muito próximo do gênero Psychotria subgênero Heteropsychotriae L. (Nepokroeff et al. 1999). A separação ocorre devido a presença de tubo da corola atrativo e colorida e produção abundante de néctar, o que caracteriza a ornitofilia (Taylor 1997) e diferencia do gênero Psychotria L. que recebe visita preferencialmente de insetos (Bawa \& Beach 1983; Kress \& Beach 1994; Taylor 1997). O gênero Palicourea compreende cerca de 200 espécies de arbustos e pequenas árvores, tipicamente membros do sub-bosque de matas tropicais e poucas delas ocorrem em savanas, distribuídos somente nos trópicos do Novo Mundo (Taylor 1997). O gênero foi considerado quase exclusivamente distílico, devido ao fato dessa característica ser definida como ancestral no gênero (Taylor 1997).

A fim de enriquecer o conhecimento da heterostilia em Rubiaceae, e no bioma Cerrado, o estudo visa caracterizar o sistema reprodutivo, as características distílicas, a fenologia e a polinização em Palicourea crocea (Sw.) Roem. \& Schult. (Rubiaceae).

\section{Material e Métodos}

Área de estudo

$\mathrm{O}$ trabalho foi realizado em uma área entre os municípios de Itumbiara e Buriti Alegre de Goiás, e abrange cerca de 60 hectares (18 $\left.20^{\prime} 59,56^{\prime \prime} \mathrm{S}, 49^{\circ} 4^{\prime} 18,38^{\prime \prime} \mathrm{W}\right)$, tendo como vegetação predominante uma Floresta Estacional Semidecidual, em meio a áreas de cultivo (cana- 
de-açúcar) e pastagens. O clima da área é do tipo AW (Köppen 1958) com estação seca de maio a setembro e chuvosa de outubro a abril. A espécie se apresenta de forma pouco dominante na área, com vários indivíduos ocupando o sub-bosque da vegetação.

\section{Espécie estudada}

Palicourea crocea (Sw.) Roem. \& Schult. é uma arvoreta com até $4 \mathrm{~m}$, folhas 6-17 $\times 5-9 \mathrm{~cm}$, estípulas persistentes, inflorescências em panículas cimosas piramidais e terminais, emitidas entre um par de folhas, flores tubulares amarelas com tubo de 9-15 mm, distílicas, estames e pistilo amarelados, pedicelo e a raque da inflorescência avermelhados, os frutos são negros arroxeados.

\section{Fenologia}

Para o registro fenológico, foram marcados, aleatoriamente, 16 indivíduos distantes no mínimo 20 metros entre si e bem distribuídos na área de estudo, sendo oito indivíduos brevistílicos e oito indivíduos longistílicos, marcados com linhas de cores distintas. As observações fenológicas foram realizadas mensalmente durante as atividades vegetativas e quinzenalmente quando os indivíduos se encontravam na fase reprodutiva. Foram registradas as seguintes fenofases: emissão de botões florais (brotamento), flores abertas, presença de frutos verdes, presença de frutos maduros, e queda foliar. As fenofases foram avaliadas seguindo um padrão de notas de intensidade de acordo com Fournier (1974), onde 0- indica ausência de fenofase; 1 - de $1 \%$ a $25 \%$ da fenofase; 2 - de $26 \%$ a $50 \%$ da fenofase; 3 - de $51 \%$ a $75 \%$ da fenofase e $4-$ de $76 \%$ a $100 \%$ da fenofase. Os dados foram coletados individualmente e depois obteve-se média das fenofases. Para evitar erros na avaliação, todos os dados foram coletados pelo mesmo pesquisador. Nas observações também foi avaliado o sincronismo entre os indivíduos.

\section{Biologia floral}

Trinta botões florais em pré-antese foram marcados aleatoriamente, em 10 indivíduos, sendo três botões por indivíduo, usando linhas e fitas coloridas. Registrou-se o horário de antese floral (definido pela separação dos lóbulos da corola), tempo de vida da flor-antese (avaliada pelas características de cor e brilho da corola), receptividade estigmática (a partir da separação dos lóbulos estigmáticos) e liberação de grãos de pólen (observação direta das anteras e identificação de pólen). Além dessas observações, foram registradas características de cor e odor das flores. Os métodos foram seguidos de Coelho \& Barbosa $(2003,2004)$, e Consolaro et al. (2009).

\section{Morfometria floral e razão entre morfos}

Os caracteres florais, incluindo a distilia, foram avaliados em 80 flores (40 flores de cada morfo), coletadas de forma aleatória em cerca de 20 indivíduos de cada morfo. As medidas realizadas foram feitas usando-se paquímetro manual com medições em milímetros. Obteve-se medidas do tamanho da corola (da base do ovário até as pétalas); da altura dos estames (da base da corola até a região mais alta das anteras); tamanho das anteras (medida a partir de uma antera por flor); altura do estilete (da base da corola até a parte mais alta do estigma) e tamanho do estigma.

\section{Hercogamia recíproca}

As medidas de altura de estilete de um morfo com a altura dos estames de outro morfo (hercogamia recíproca) foram avaliadas usandose três métodos: Richards \& Koptur (1993) avaliando o nível de hercogamia em órgãos separadamente, onde $\mathrm{R}_{\mathrm{H}}$ (índice de reciprocidade de órgãos recíprocos altos são avaliados a partir de anteras de flores brevistiladas e estigma de flores longistiladas) e $\mathrm{R}_{\mathrm{L}}$ (índice de reciprocidade de órgãos recíprocos baixos, avaliados a partir de anteras de flores longistiladas e estigma de flores brevistiladas), a partir da seguinte equação: altura das anteras de um morfo menos a altura do estigma do morfo oposto, dividido pela altura das anteras de um morfo mais a altura do estigma do morfo oposto. Os valores de um indivíduo foram calculados com os valores de todos os demais indivíduos amostrados, obtendo-se posteriormente a média do índice. Para os cálculos de Sánchez et al. (2013) obteve-se um único valor de $R$ (índice de reciprocidade) para a população, não havendo diferença entre os morfos. Já a avaliação do valor absoluto da diferença entre altura de anteras e estigmas das flores individuais, usado por Faivre \& McDade (2001), foi realizado a partir da subtração entre altura das anteras altas com o estigma baixo e altura do estigma alto com as anteras baixas, obtendo-se sempre valores positivos, os quais foram testados através do teste não paramétrico KruskalWallis $(\mathrm{P}<0,05)$, onde valores não significativos indicam homogeneidade da separação estigma antera e possível reciprocidade. 
Sistema reprodutivo

e incompatibilidade

O sistema reprodutivo foi testado a partir de polinizações manuais realizadas em 172 flores previamente ensacadas para evitar a contaminação com pólen, além de 97 flores que foram usadas como controle. Foram realizados testes de autopolinização manual $(\mathrm{n}=62)$, polinização cruzada intramorfo (ilegítima) $(\mathrm{n}=50)$, polinização cruzada intermorfo (legítima) $(\mathrm{n}=45)$ apomixia $(\mathrm{n}=25)$ e polinização natural (controle) $(\mathrm{n}=97)$ para avaliar a eficiência dos polinizadores. Foi calculado o Índice de Auto-Incompatibilidade (ISI), determinado pela razão entre a proporção da produção de frutos por autopolinização e por polinização cruzada legítima (Bullock 1985). Também foi realizado o cálculo do Índice de Eficiência Reprodutiva dos polinizadores (IER), dado pela razão entre a produção de frutos do tratamento controle e da polinização cruzada intermorfo (legítima) (Ruiz \& Arroyo 1978). Foi observado o crescimento de tubos polínicos em 60 pistilos polinizados manualmente, sendo 20 de polinizações cruzadas legítimas (dez brevistiladas e dez longistiladas), 20 de polinizações cruzadas ilegítimas (dez de cada morfo) e 20 de autopolinizações (dez de cada morfo), sendo estes pistilos de 20 indivíduos, e coletados dez horas após a polinização manual. Esses pistilos foram submetidos à técnica de coloração de Martin (1959) e observados em microscopia de epifluorescência (microscópio Olympus B51 com epifluorescência e filtro DAPI $350 \mathrm{~nm}$. A fotos foram capturadas com câmera Olympus DP70 acoplada ao microscópio) para verificar o crescimento dos tubos polínicos e identificar possíveis barreiras de incompatibilidade.

\section{Visitantes florais e avaliação}

\section{de néctar}

Foram realizadas observações diretas para definição dos visitantes florais, totalizando 80 horas de observação, distribuídas ao longo de todo o dia. Como a flor dura cerca de 24 horas, e após 12 horas a corola já murchou, não foram realizadas observações noturnas. Cada toque do visitante na flor foi considerado uma visita, sendo possível registrar o número de visitas por intervalo de tempo. Insetos visitantes foram coletados para posterior identificação. Para registro do volume de néctar, foram ensacadas 40 flores brevistiladas e 40 flores longistiladas em pré-antese e, ao final da tarde do dia seguinte (ca. $16 \mathrm{~h}$ ), o néctar foi totalmente retirado, com auxílio de capilares de vidro $(10 \mu \mathrm{l})$.
A concentração média em equivalentes de sacarose foi medida com o auxílio de refratômetro manual (Atto, WYT- 32ATC) e os dados transformados em miligramas de açúcar disponível por flor (Kearns \& Inouye 1993; Dafni et al. 2005). Além da avaliação de néctar total foi avaliada a dinâmica de secreção de néctar por intervalo de tempo, entre as 07:00 h e 16:00 h, com cinco avaliações, em 12 flores de cada morfo, usando as mesmas metodologias da avaliação de néctar total.

\section{Análises estatísticas}

Para verificar diferenças entre os dados da morfometria foi utilizado o teste $t$ de Student. Também foi aplicado o teste Exato de Fisher para comparar a frequência de formação de frutos entre autopolinização manual e polinizações cruzadas, além do teste de Qui-quadrado (frequências iguais) para avaliar a razão entre os morfos na área. O teste não paramétrico Kruskal-Wallis foi utilizado para avaliação das médias de produção de néctar e reciprocidade entre os morfos. Para avaliar a influência do tamanho da corola na altura das anteras usou-se regressão linear simples. As análises dos dados foram realizadas utilizando os programas estatísticos Systat 10.2 e Bioestat 5.0.

\section{Resultados}

Fenologia

A espécie apresenta uma caducifolia relativamente baixa durante grande parte do ano, mas com um aumento na perda de folhas entre os meses de junho e outubro (Fig. 1), período de maior déficit hídrico. A brotação segue um padrão sazonal, com maior brotamento no final da estação seca e início da estação chuvosa, se mantendo relativamente contínua e em baixa intensidade durante todo o restante do ano. As inflorescências e os primeiros botões se formam após o início da estação chuvosa, em meados de novembro, com as primeiras flores abrindo no início de dezembro e alcançando maior intensidade de botões e flores nos meses de janeiro e fevereiro, respectivamente, respondendo de forma bem sazonal a disponibilidade de água. A formação de frutos inicia-se ainda no mês de dezembro, demorando cerca de dois meses e meio até os primeiros frutos maduros estarem disponíveis para dispersão, a qual se prolonga até início do mês de junho, com pico de frutos maduros no mês de abril. O período de floração total se mostra com um intervalo intermediário, com cerca de quatro meses de floração (Fig. 1). O sincronismo entre 


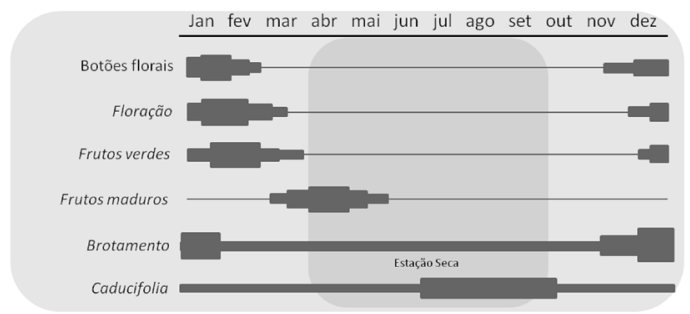

Figura 1 - Fenologia Palicourea crocea (Rubiaceae) em área de Mata Estacional semi decidual na região Sul do estado de Goiás-Brasil. A largura da linha indica a intensidade da fenofase de acordo com Fournier (1974), com 4 níveis de intensidade: $0-25 \% ; 26-50 \% ; 51-75 \%$ e $75-100 \%$.

Figure 1 - Phenology of Palicourea crocea (Rubiaceae) in area of semi deciduous seasonal forest in the South region of the state of Goiás-Brazil. The line width indicates the intensity of phenophase according to Fournier (1974), with 4 levels of intensity: $0-25 \% ; 26-50 \% ; 51-75 \%$ and $75-100 \%$.

os indivíduos foi relativamente alto, com $75 \%$ dos indivíduos apresentando a mesma fenofase, sem diferença entre os morfos. A sazonalidade da área, principalmente com relação à disponibilidade de água, pode explicar muito das respostas fenológicas da espécie, como floração anual e logo após o final da estação seca.

\section{Biologia floral}

Palicourea crocea possui flores amarelas, tetrâmeras ou pentâmeras, dispostas em inflorescências terminais cimosas paniculadas (Fig. 2 ), com cerca de $11,12 \pm 3,47 \mathrm{~cm}$ de comprimento e com uma média de $38 \pm 14$ flores $(n=40)$, dispostas entre um par de folhas. Apresentam toda a raque e o pedicelo das flores de coloração vermelha (Fig. 2a) o que amplia o contraste de cores e facilita a visualização pelos visitantes. As flores apresentam longevidade de aproximadamente 24 horas, sem odor característico, sendo que o néctar, e às vezes o pólen, são os principais recursos disponíveis aos visitantes. As flores apresentam, na parte inferior interna do tubo da corola, que é simpétala, um anel de tricomas que impede o acesso ao disco nectarífero e consequentemente, ao néctar, restringindo a coleta de néctar a certos visitantes, como formigas. Outra característica, facilmente observada nas flores, é a presença de uma giba proeminente e localizada na porção proximal do tubo floral, que favorece o acúmulo de néctar (Fig. 2b), e deixa a flor com características zigomorfas. Na abertura do tubo da corola é possível visualizar a borda externa das lacínias com uma coloração avermelhada, o que acentua ainda mais o contraste e pode ampliar a visitação (Fig. 2a). A abertura da corola ocorre entre 05:30 e 07:00 horas, aparentemente influenciada pela temperatura e umidade do dia, mas com alto sincronismo $(>80 \%)$ entre os indivíduos $(\mathrm{n}=10)$. A variação na altura dos estames e dos estigmas nas flores é bem evidente, ficando fácil a caracterização dos morfos entre os indivíduos, e as avaliações de visitantes, fenologia e demais características entre os morfos. Uma característica interessante, e não muito comum em espécies distílicas, é que em nenhum dos morfos as estruturas reprodutivas altas ultrapassam o comprimento da corola, ficando sempre dentro da flor (Fig. 2b), isso pode restringir o contato de certos visitantes. Os estames são epipétalos e, avaliando a influência da corola na altura das anteras, o teste de regressão evidenciou $\mathrm{R}^{2}=0,39$ e $\mathrm{p}<0,001$ para o morfo brevistílico e $\mathrm{R}^{2}=0,04$ e $\mathrm{p}=0,115$ para o morfo longistílico, demonstrando que o tamanho da corola influencia de forma significativa a altura das anteras no morfo brevistílico, mas não afeta em nada a altura das anteras no morfo longistílico (Fig. 3). As anteras são dorsifixas e com deiscência longitudinal. As corolas permanecem na inflorescência até a manhã do dia seguinte, mas apresentando senescência, e quando são tocadas, caem, deixando somente o disco nectarífero e o ovário evidente. O ovário é ínfero e apresenta dois óvulos que se desenvolvem em sementes em $62 \%$ dos frutos formados $(n=50)$. O estilete e os estigmas são amarelos e apresentam dimorfismo. As avaliações florais não indicaram nenhum tipo de dicogamia, sendo que o pólen e o estigma já estão viáveis logo após a abertura das flores. Os frutos estão prontos para dispersão cerca de 3 meses após a polinização e amadurecem de forma lenta, favorecendo a ação dos dispersores (Fig. 2c,d).

\section{Morfometria e razão entre morfos}

Palicourea crocea se mostrou como distílica típica, sendo caracterizados dois morfos bem distintos, e com separação espacial entre anteras e estigmas em ambos os morfos de forma marcante (Fig. 2b).

O tamanho da corola apresentou diferença significativa entre os morfos e se mostraram com $12,73 \pm 1,29 \mathrm{~mm}$ (longistila) e $14,46 \pm$ $1,44 \mathrm{~mm}$ (brevistila) de comprimento. Houve diferença significativa entre os morfos em todas as características avaliadas (Tab. 1). A razão entre morfos foi avaliada na área, e a população se 

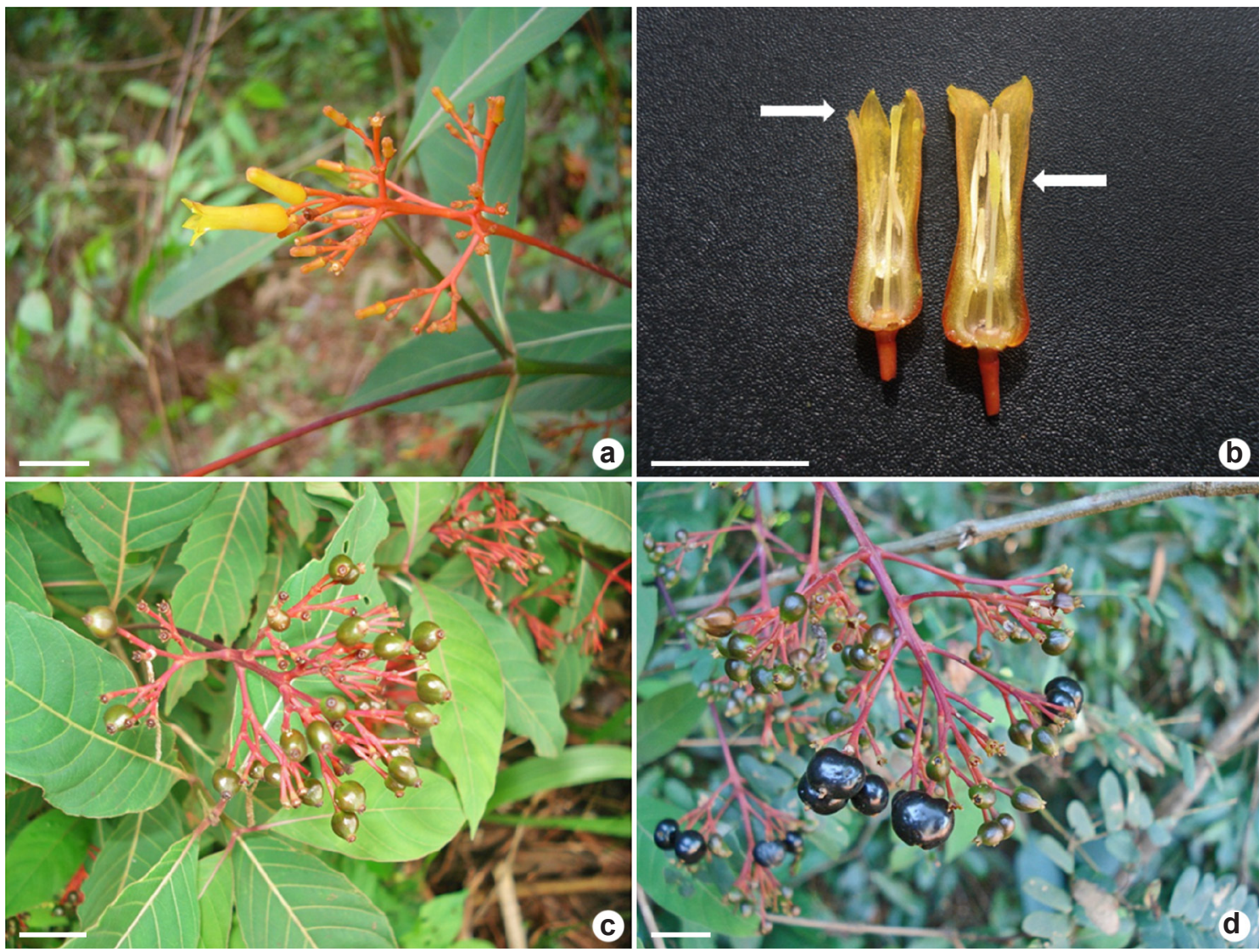

Figura 2 - a-d. Aspecto geral de Palicourea crocea em área de Mata estacional semi decidual em Itumbiara, GO - a. detalhe da inflorescência de indivíduos na área de estudo; b. detalhe das flores longi e brevistílica, setas mostram a altura dos estigmas; c. detalhe dos frutos verdes em inflorescência terminal cimosa paniculada; d. detalhe dos frutos maduros e verdes. Barras: $1 \mathrm{~cm}$.

Figure 2 - a-d. General aspect of Palicourea crocea in a semi deciduous forest area in Itumbiara, GO - a. detail of the inflorescence of individuals in the study area; $b$. detail of the pim and thrum flowers, arrows show the height of stigmas; c. detail of green fruits in paniculate terminal cimose inflorescence; d. detail of ripe and green fruit. Bars: $1 \mathrm{~cm}$.

mostrou isoplética com 15 indivíduos brevistílicos e 16 indivíduos longistílicos.

\section{Hercogamia}

A hercogamia recíproca foi testada a partir de 40 flores de cada morfo, através das medidas das estruturas reprodutivas (altura de pistilo e de estames), sendo comparado o órgão alto de um morfo, com o órgão alto do outro morfo, o mesmo se repetindo com os órgãos baixos. Na avaliação do índice de reciprocidade, seguindo o teste de Richards \& Koptur (1993), ambas as alturas se mostram com níveis altos de reciprocidade, visto que apresentaram valor de 0,046 avaliando estruturas reprodutivas altas $\left(\mathrm{R}_{\mathrm{H}}\right)$, e valor de $-0,009$ avaliando as estruturas reprodutivas baixas
$\left(R_{L}\right)$. Estes valores confirmam a presença de distilia na população, mas destacam também que as peças reprodutivas baixas são mais recíprocas do que as peças altas, visto que se aproxima mais de zero e indicam alta reciprocidade. Outra informação interessante é que os estames são maiores do que o estigma nas peças altas e o estigma é mais alto do que os estames nas peças baixas (Fig. 4), o que pode influenciar o fluxo de pólen. Quando avaliados pelo teste de Sánchez et al. (2013), obteve-se valor de R $=0,892$, demonstrando grande reciprocidade. Para esse teste, quanto mais próximo de um (1), maior o índice de reciprocidade (Tab. 1). No teste avaliando os valores absolutos da diferença entre a altura dos pistilos e a altura das anteras em cada 


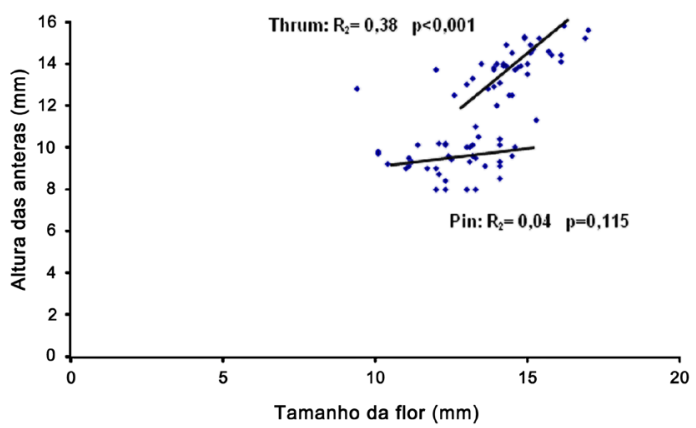

Figura 3 - Regressão linear entre tamanho da flor e altura das anteras nos dois morfos florais de Palicourea crocea no sub bosque em Floresta Estacional Semi decidual na região Sul do estado de Goiás. Valores de regressão linear simples para cada morfo.

Figure 3 - Linear regression between flower size and height of anthers in the two floral morphs of Palicourea crocea in understory in Semi Seasonal Forest in the southern region of the state of Goiás. Values of simple linear regression for each morpho.

flor, de acordo com Faivre \& McDade (2001), observou-se que existe diferença significativa na separação das peças reprodutivas entre os morfos $(\mathrm{U}=1224,500, \mathrm{p}<0,001)$, o que causa certa dúvida na aplicabilidade desse teste, pois essa diferença indicaria uma menor reciprocidade, o que não foi confirmada pelos outros testes realizados (Figs. 4 e 5).
Sistema reprodutivo

e incompatibilidade

A população de Palicourea crocea mostrouse auto e intramorfo incompatível, com uma formação de frutos bem maior em polinizações cruzadas intermorfos, comparada com os outros tipos de polinizações (Tab. 2). A formação de frutos por autopolinização foi baixa, apresentando uma maior porcentagem em flores brevistilas e pode ser resultado de contaminação durante a manipulação das flores, o mesmo acontecendo com as polinizações cruzadas ilegítimas, já que nos testes de crescimento de tubos polínicos, tanto autopolinizações, quanto polinizações cruzadas intramorfo - ilegítimas, os tubos polínicos não alcançaram a base do estilete, sendo interrompidos na porção média do estilete para o morfo longistílico e no estigma para o morfo brevistílico, onde fica evidente uma maior deposição de calose nos locais de interrupção (Fig. 6). Enquanto que para os cruzamentos legítimos os tubos polínicos alcançaram a base do estilete e em alguns casos foram vistos resquícios de tubos próximos dos óvulos. O índice de auto incompatibilidade (ISI) alcançou um valor de 0,13 para o morfo brevi e de 0,05 para o longi indicando auto incompatibilidade (Tab. 2), pois nenhum valor ultrapassou 0,25 , valor limite para

Tabela 1 - Morfometria floral e índices de reciprocidade em Palicourea crocea (Rubiaceae) no sub bosque em Floresta Estacional Semi decidual na região Sul do estado de Goiás-Brasil.

Table 1 - Floral morphometry and reciprocity indices in Palicourea crocea (Rubiaceae) in the understory in Semi deciduous seasonal forest in the southern region of the state of Goiás-Brazil.

\begin{tabular}{|c|c|c|}
\hline \multicolumn{3}{|c|}{ Morfometria floral e hercogamia em Palicourea croceoides (Rubiaceae) } \\
\hline Caracteres florais & Longistilas & Brevistilas \\
\hline Tamanho da corola * & $12,73 \pm 1,29$ & $14,46 \pm 1,44$ \\
\hline Altura do estilete * & $12,71 \pm 0,88$ & $9,66 \pm 0,72$ \\
\hline Altura da antera * & $9,49 \pm 0,80$ & $13,94 \pm 0,93$ \\
\hline Tamanho do estigma * & $3,64 \pm 0,59$ & $3,92 \pm 0,57$ \\
\hline Tamanho do antera * & $2,18 \pm 0,65$ & $3,14 \pm 0,71$ \\
\hline Separação estigma antera * & $3,22 \pm 1,07$ & $4,29 \pm 1,06$ \\
\hline Índice de Richards \& Koptur (1993) ** & $\mathrm{R}_{\mathrm{H}}: 0,046$ & $\mathrm{R}_{\mathrm{L}}:-0,009$ \\
\hline Índice de Sánchez et al. (2008) *** & \multicolumn{2}{|c|}{ R: 0,892} \\
\hline
\end{tabular}

* Morfos florais apresentam diferença significativa $\mathrm{p}<0,05$.

** $\mathrm{R}_{\mathrm{H}}=$ índice de reciprocidade entre os órgãos altos (anteras de flores brevistilas e estigma de flores longistilas); $\mathrm{R}_{\mathrm{L}}=$ índice de reciprocidade entre órgãos baixos (anteras de flores longistilas e estigma de flores brevistilas (Richards \& Koptur 1993)).

*** $\mathrm{R}=$ índice de reciprocidade de Sánchez et al. (2013). 


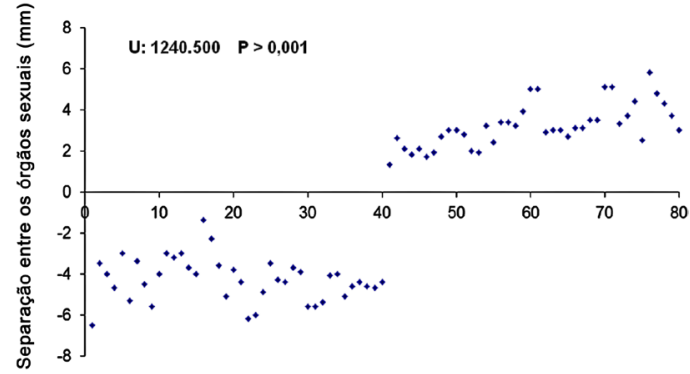

Figura 4 - Separação entre os órgãos sexuais nos dois morfos de Palicourea crocea no sub bosque em Floresta Estacional Semi decidual na região Sul do estado de Goiás. Teste de Kruskal-Walis avaliando a similaridade dos valores absolutos.

Figure 4 - Separation between the sexual organs in the two morphs of Palicourea crocea in the understory in Semi deciduous seasonal forest in the southern region of the state of Goiás-Brazil. Kruskal-Walis test evaluating the similarity of absolute values.

a incompatibilidade de acordo com Bullock (1985). Já o índice de eficiência dos polinizadores indicou valores de 0,76 para o morfo brevi e de 0,73 para o morfo longi, demonstrando uma boa eficiência dos polinizadores na transferência de pólen, mas cerca de $20 \%$ menor se comparada com a polinização manual (Tab. 2).
Visitantes florais e avaliação de néctar

A gama de visitantes florais em $P$. crocea é muito ampla recebendo visitas de organismos vertebrados (beija-flores) e invertebrados (abelhas, borboletas e mariposas) (Fig. 7; Tab. 3), além de formigas e gafanhotos, estes últimos com comportamento pilhador. Os beija-flores e as mariposas são os visitantes mais frequentes e com comportamento mais legítimo, se movimentando muito entre os indivíduos e visitando quase todas as flores abertas. Os beija-flores podem ser divididos em dois grandes grupos, aqueles que demarcam território e defendem contra a visita de outros beija-flores (Eupetomena macroura) e aqueles que visitam em intervalos maiores de tempo e demonstram seguir uma rota de forragemento (Thalurania furcata). Outros beija-flores como Amazilia fimbriata foram considerados visitantes pouco frequentes. As abelhas, principalmente Eulaema nigrita (Fig. 7a) são também frequentes, mas visitam menos flores do que os beija flores $\mathrm{e}$ as mariposas. As abelhas de maior porte (E. nigrita e Epicharis flava) coletam néctar, já as menores (Trigona sp.) (Fig. 7b) geralmente permanecem na abertura da corola coletando pólen. Outras abelhas foram observadas pilhando flores, mas não foi possível sua coleta e identificação.

Tabela 2 - Avaliação do sistema reprodutivo em Palicourea crocea (Rubiaceae) no sub bosque em Floresta Estacional Semi decidual na região Sul do estado de Goiás.

Table 2 - The Evaluation of breeding systems in Palicourea crocea (Rubiaceae) in the understory in Seasonal Forest Semi decidual in the southern region of the state of Goiás.

\begin{tabular}{|c|c|c|c|c|c|c|c|c|}
\hline \multirow{2}{*}{ Tratamento } & \multicolumn{3}{|c|}{ Morfo Brevistílico } & \multicolumn{5}{|c|}{ Morfo Longistílico } \\
\hline & $\mathbf{N}^{0}$ flores & $\mathrm{N}^{0}$ frutos & $\%$ & & $\mathbf{N}^{0}$ flores & $\mathrm{N}^{0}$ frutos & $\%$ & \\
\hline Auto polinização manual & 33 & 4 & 12.1 & $\mathrm{aA}$ & 29 & 1 & 3.4 & $\mathrm{aA}$ \\
\hline $\begin{array}{l}\text { Polinização cruzada Intermorfo - } \\
\text { Legítima }\end{array}$ & 25 & 23 & 92.0 & $\mathrm{bA}$ & 20 & 15 & 75.0 & $\mathrm{bA}$ \\
\hline $\begin{array}{l}\text { Polinização cruzada Intramorfo - } \\
\text { Ilegítima }\end{array}$ & 23 & 4 & 17.4 & $\mathrm{aA}$ & 17 & 2 & 11.8 & $\mathrm{aA}$ \\
\hline Apomixia & 10 & 0 & 0.0 & $\mathrm{cA}$ & 15 & 0 & 0.0 & $\mathrm{cA}$ \\
\hline Polinização Natural - Controle & 46 & 32 & 69.6 & $\mathrm{bA}$ & 51 & 28 & 54.9 & $\mathrm{bA}$ \\
\hline Índice de Auto Incompatibilidade (ISI) & & 0.13 & & & & 0.05 & & \\
\hline $\begin{array}{l}\text { Índice de Eficiência Reprodutiva dos } \\
\text { Polinizadores (IER) }\end{array}$ & & 0.76 & & & & 0.73 & & \\
\hline
\end{tabular}

Letras minúsculas diferentes na mesma coluna indicam diferença significativa entre os tratamentos. $p<0,005$ 

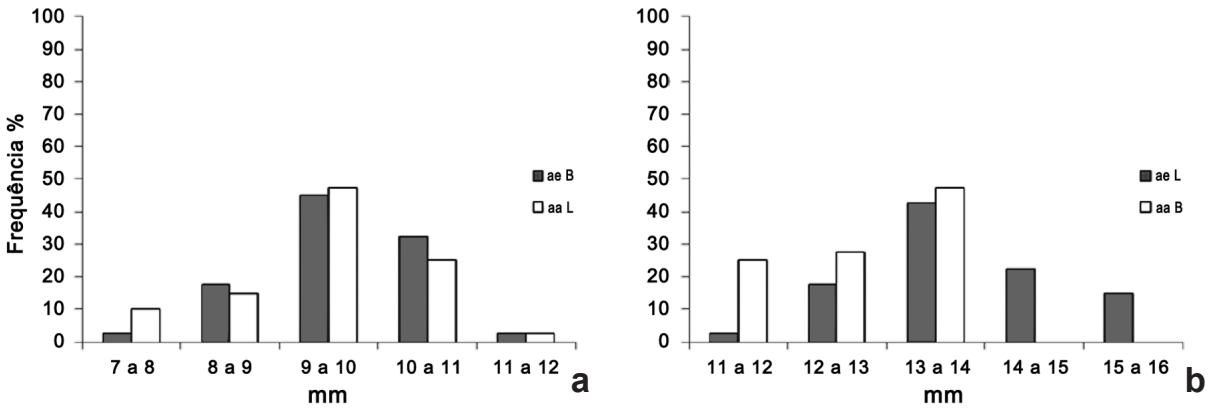

Figura 5 - Distribuição dos indivíduos com base nas alturas ( $\mathrm{mm}$ ) de estigma (ae) e anteras (aa) de flores brevistilas (B) e longistilas (L) de Palicourea crocea (Rubiaceae) em uma área de Mata estacional semi decidual região Sul do estado de Goiás-Brasil - a. altura do estigma de flores B e anteras de flores L (órgãos baixos); b. altura do estigma de flores L e anteras de flores B (órgãos altos).

Figure 5 - Distribution of individuals based on height ( $\mathrm{mm}$ ) of stigma (ae) and anther (aa) of thrum flowers (B) and pin (L) of Palicourea crocea (Rubiaceae) in an area of seasonal deciduous forest in the southern region of Goiás state -Brazil - a. height of stigma of flowers B and anthers of flowers L (low organs); b. stigma height of flowers L and anthers of flowers B (tall organs).
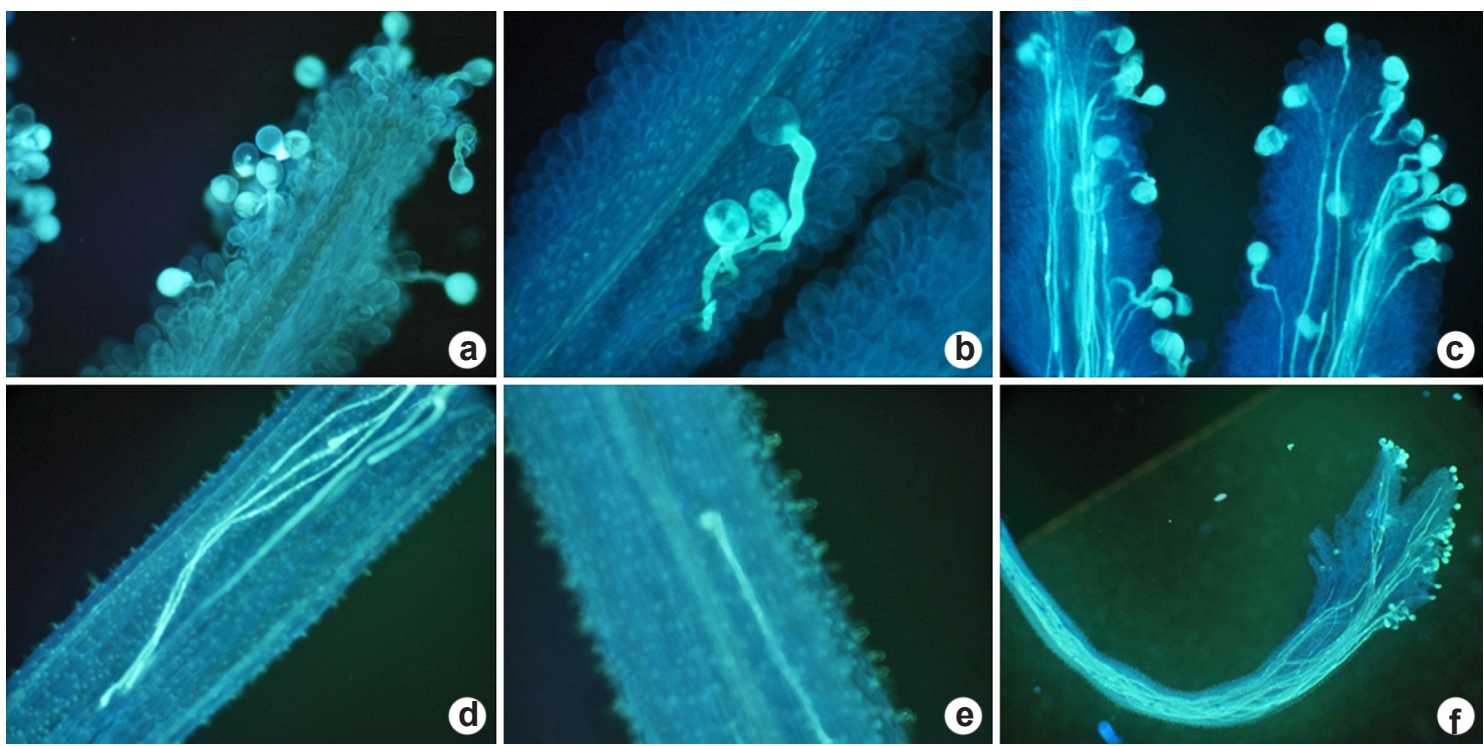

Figura 6 - Avaliação do crescimento de tubos polínicos em pistilos manualmente polinizados de Paliourea crocea em área de Mata estacional semi decidual no sul do estado de Goiás - a. auto polinização no morfo brevistílico - interrupção do tubo polínico no estigma; b. polinização cruzada intramorfo (ilegítima), no morfo brevistílico interrupção do tubo polínico no estigma; c. polinização cruzada intermorfo (legítima), no morfo brevistílico - nenhuma interrupção dos tubos polínicos. d. auto polinização no morfo longistílico - interrupção do tubo polínico no estilete; e. polinização cruzada intramorfo (Ilegítima), no morfo longistílico - interrupção do tubo polínico no estilete; f. polinização cruzada intermorfo (Legítima), no morfo longistílico - nenhuma interrupção dos tubos polínicos, crescem até a base do estilete.

Figure 6 - Evaluation of the growth of pollen tubes in manually pollinated pistils of Paliourea crocea in an area of semi deciduous seasonal forest in the south of the state of Goiás. a. self pollination in the thrum morph - interruption of the pollen tube in the stigma; b. intramorphic cross-pollination (illegitimate), in the thrum morph - interruption of the pollen tube in the stigma; c. cross-pollination (legitimate), in the thrum morph - none interruption of pollen tubes. d. self-pollination in the pin morpho - interruption of the pollen tube in the stylet; and. intramorphic cross-pollination (illegitimate), in the longistilic morpho - interruption of the pollen tube in the stylet; f. cross-pollination (Legitimate), in the pin morpho - no interruption of pollen tubes, grow to the base of the stylus. 

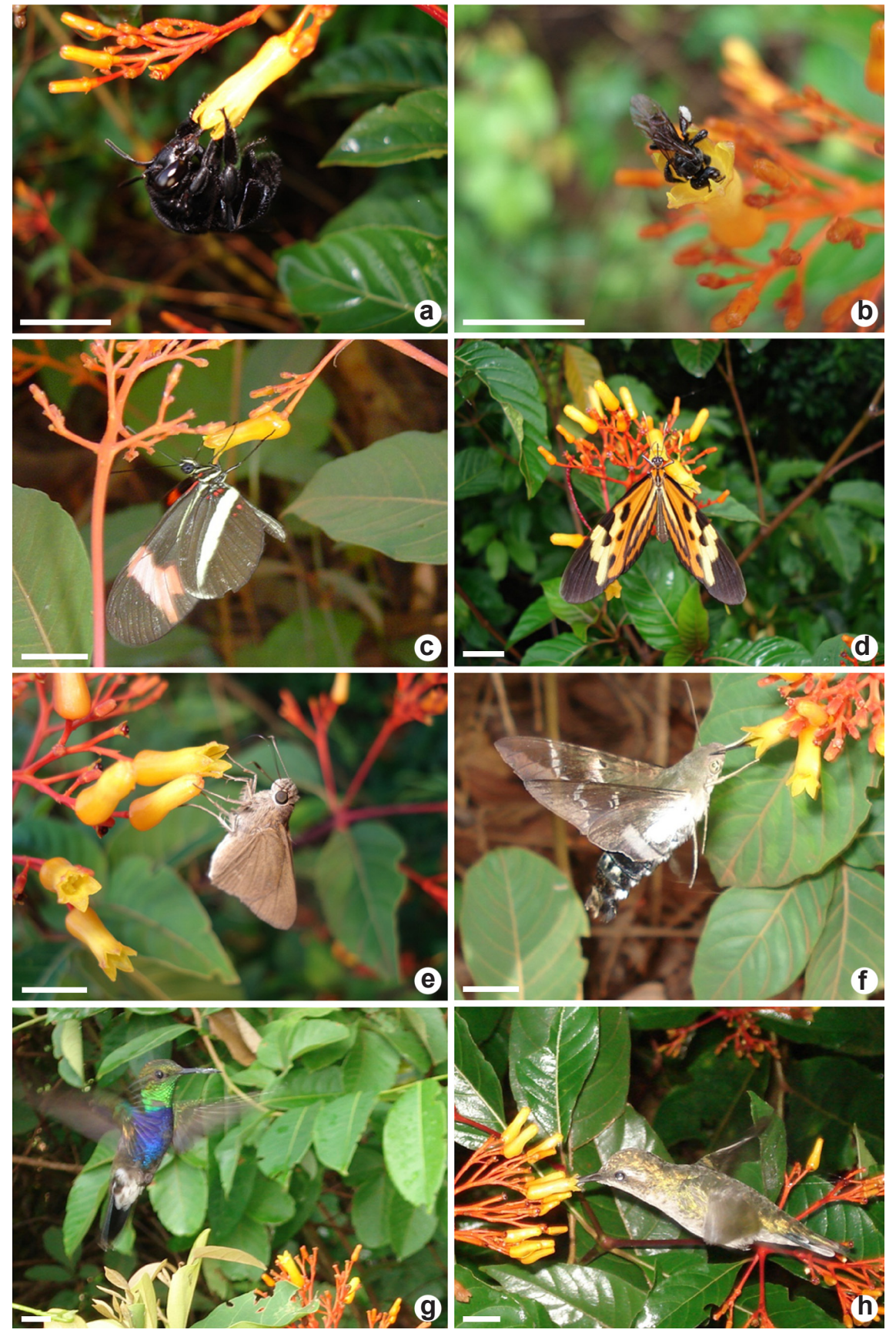

Figura 7 - Principais visitantes florais em Palicourea crocea em área de Mata estacional semi decidual no sul do estado de Goiás - a. detalhe de Eulaema nigrita (Hymenoptera, Apidae, Euglossini), introduzindo a língua para tomar néctar; b. Trigona sp. - Hymenoptera, Apinae, Meliponini coletando pólen na entrada da corola; c-d. espécies de Heliconius sp. coletando néctar; e-f. Aellopos titan (Cramer 1777) (Lepidoptera - Sphingidae) coletando néctar em flor; g. macho de Thalurania furcata Baeri com diversos grãos de polen sobre o bico (seta). h. fềmea de Thalurania furcata visitando flor. Barras: $1 \mathrm{~cm}$.

Figure 7 - Main floral visitors in Palicourea crocea in area of semi deciduous seasonal forest in south state of Goiás - a. detail of Eulaema nigrita (Hymenoptera, Apidae, Euglossini), introducing the tongue to take nectar; b. sp. - (Hymenoptera, Apinae, Meliponini) collecting pollen at the entrance to the corolla; c-d. species of Heliconius sp. collecting nectar; e-f. Aellopos titan (Cramer 1777) (Lepidoptera - Sphingidae) collecting nectar in flower; g. male of Thalurania furcata Baeri with some pollen grains on the beak (arrow). h. female from Thalurania furcata visiting flower. Bars: $1 \mathrm{~cm}$. 
Tabela 3 - Relação dos principais visitantes florais em Palicourea crocea (Rubiaceae) no sub bosque em Floresta Estacional Semi decidual na região Sul do estado de Goiás.

Table 3 - List of main floral visitors in Palicourea crocea (Rubiaceae) in the understory in semi deciduous seasonal forest in south state of Goiás.

\begin{tabular}{lll}
\hline Ordem & Família & Espécie \\
\hline Hymenoptera & Apidae & Trigona sp. \\
& & Eulaema nigrita $*$ \\
& & Apis mellifera \\
Lepidoptera & Euglossinae & Epicharis flava \\
& Sphingidae & Euglossa sp. \\
& Nymphalidae & \\
Apodiformes & Hesperiidae & Aellopos titan $*$ \\
& Trochilidae & Heliconius erato \\
& & Urbanus sp. \\
& & Chlorostilbon aureoventris $*$ \\
\hline
\end{tabular}

* Potenciais polinizadores de Palicourea crocea, observando comportamento e frequência das visitas.

As borboletas são visitantes frequentes, mas visitam poucas flores por indivíduo. Permanecem um tempo maior nas flores abertas em busca de néctar (Fig. 7c,d), porém sua frequência é menor que das abelhas e do que as mariposas. As mariposas são bem frequentes e com visitas legítimas, tocando as estruturas reprodutivas em todas as visitas (Fig. 7e,f). Dessa forma podemos considerar como polinizadores efetivos os beija-flores, as abelhas grandes e as mariposas e (Fig. 7, Tab. 3). A produção de néctar ocorre durante toda a antese da flor, ficando evidente que o néctar produzido nas primeiras horas do dia é mais energético do que o néctar produzido posteriormente (Tab. 4). Em avaliações feitas no final do período de antese, avaliando néctar acumulado, não houve diferença significativa no volume, concentração e disponibilidade de açúcar entre os morfos (Tab. 5).

\section{Discussão}

\section{Fenologia}

As espécies de Palicourea descritas em trabalhos na região Neotropical demonstram padrões fenológicos similares, com floração de 3 a 7 meses (Machado et al. 2010; Mendonça \& Anjos
2006; Coelho \& Barbosa 2003). A espécie avaliada apresenta floração iniciando com as chuvas, no mês de outubro/novembro e se estendendo até janeiro/ fevereiro, em meados da estação chuvosa, similar a outros trabalhos no Cerrado (Machado et al. 2010; Mendonça \& Anjos 2006; Coelho \& Barbosa 2003), com esses dados podemos classificar $P$. crocea como sendo uma espécie que apresenta tipo de floração anual intermediário, de acordo com Newstron et al. (1994) ou ainda do tipo "stedystate" de acordo com Gentry (1974), esses padrões de floração descrevem a produção de poucas flores por dia, durante um tempo relativamente longo (um a cinco meses) no caso da espécie em estudo quatro meses, sendo similar ao comportamento de dispersão. Esses padrões podem estar associados diretamente ao comportamento dos visitantes e dos dispersores (Teixeira \& Machado 2004; Consolaro 2008), pois aumentam a fidelidade dos visitantes devido a maior disponibilidade de recursos por um longo tempo. No caso da espécie avaliada, relacionado com os principais visitantes florais, beija-flores, abelhas e mariposas, que apresentam ampla capacidade de locomoção e dessa forma se movimentam entre as plantas, buscando recursos e otimizando o fluxo de pólen. 
Tabela 4 - Avaliação do néctar produzido em intervalos distintos nos morfos florais de Palicourea crocea (Rubiaceae) no sub bosque em Floresta Estacional Semi decidual na região Sul do estado de Goiás.

Table 4 - Evaluation of nectar produced at different intervals in the floral morphs of Palicourea crocea (Rubiaceae) in the understory in semi deciduous seasonal forest in south state of Goiás.

\begin{tabular}{ccc}
\hline \multirow{2}{*}{ Horário de avaliação } & \multicolumn{2}{c}{ Quantidade açúcar - mg (Morfos) } \\
\cline { 2 - 3 } & Longistilo $(\mathbf{n}=\mathbf{1 2})$ & Brevistilo $(\mathbf{n}=\mathbf{1 2})$ \\
\hline $07: 00$ & $1,44 \pm 0,47 \mathrm{a}$ & $1,12 \pm 0,73 \mathrm{a}$ \\
$08: 00$ & $0,70 \pm 0,42 \mathrm{a}$ & $0,46 \pm 0,42 \mathrm{a}$ \\
$09: 00$ & $0,28 \pm 0,18 \mathrm{a}$ & $0,26 \pm 0,40 \mathrm{a}$ \\
$10: 00$ & $0,22 \pm 0,21 \mathrm{a}$ & $0,15 \pm 0,19 \mathrm{a}$ \\
$16: 00$ & $0,89 \pm 0,79 \mathrm{a}$ & $0,53 \pm 0,56 \mathrm{a}$ \\
\hline
\end{tabular}

Letras diferentes na mesma linha indicam diferença significativa entre os morfos - $p<0,05$

Além disso, as fenofases vegetativas, seguem os padrões comumente descritos para outras Rubiaceae arbustivas no bioma Cerrado (Consolaro et al. 2005, 2011; Oliveira 2008; Consolaro 2008; Rodrigues \& Consolaro 2013), principalmente com relação à caducifólia e ao brotamento.

\section{Biologia floral}

Flores tubulares amarelas, com raques e pedicelos avermelhados, demonstrando grande contraste de cor, ausência de odor, presença de néctar abundante e fluído, e antese diurna caracterizam a espécie como ornitófila (Faegri \& van der Pijl 1979; Proctor et al. 1996). Outros dados como em Ferdinandusa speciosa Pohl (Castro \& Oliveira 2001), Manettia luteo-rubra (Vell.) Benth. (Passos \& Sazima 1995), Matettia cordifolia Mart. (Consolaro et al. 2005), Psychotria nuda (Cham. \& Schltdl.) Wawra (Buzato et al. 2000), e outras espécies de Palicourea (Sobrevila et al. 1983; Ree 1997; Contreras \& Ornelas 1999;
Coelho \& Barbosa 2003; Mendonça \& Anjos 2006; Hernandez \& Ornelas 2007; Consolaro et al. 2009; Machado et al. 2010) reforçam a ornitofilia na família Rubiaceae. Todas as informações confirmam a afirmação de Taylor (1997) sobre o predomínio de ornitofilia no gênero Palicourea.

\section{Morfometria floral e razão}

entre os morfos

Os dados morfométricos demonstram que P. crocea apresenta os polimorfismos básicos de espécies distílicas típicas, como dois morfos com diferença significativa na altura de estames e pistilos entre os morfos, além de variação no tamanho da superfície estigmática. Esses dados já haviam sido descritos por Mendonça \& Anjos, (2006). Esses polimorfismos são presentes, mas bem variados entre as espécies de Palicourea. Em trabalho relatando o gênero, Taylor (1997), destaca a distilia como uma característica exclusiva em

Tabela 5 - Avaliação do néctar total acumulado nos morfos florais de Palicourea crocea (Rubiaceae) no sub bosque em Floresta Estacional Semi decidual na região Sul do estado de Goiás.

Table 5 - Evaluation of the total nectar accumulated in the floral morphs of Palicourea crocea (Rubiaceae) in the understory in semi deciduous seasonal forest in the southern region of the state of Goiás.

\begin{tabular}{ccc}
\hline Palicourea crocea & \multicolumn{2}{c}{ Morfos } \\
\cline { 2 - 3 } & Longistilo $(\mathbf{n}=\mathbf{4 0})$ & Brevistilo $(\mathbf{n}=\mathbf{4 0})$ \\
\hline Volume microlitros - $\mu \mathrm{l}$ & $9,61 \pm 4,37 \mathrm{a}$ & $10,35 \pm 4,41 \mathrm{a}$ \\
Concentração sacarose - \% & $20,05 \pm 1,35 \mathrm{a}$ & $20,54 \pm 2,33 \mathrm{a}$ \\
Quantidade açúcar - mg & $2,06 \pm 0,96 \mathrm{a}$ & $2,23 \pm 0,81 \mathrm{a}$ \\
\hline
\end{tabular}

Letras diferentes na mesma linha indicam diferença significativa entre os morfos - $p<0,05$ 
Palicourea, porém alguns trabalhos descrevendo P. alpina (Tanner 1982), P. macrobotrys (Coelho \& Barbosa 2003), P. coriaceae (Consolaro et al. 2009) já evidenciaram a característica de homostilia dominando totalmente a população ou em vários indivíduos da população. No presente estudo a distilia típica, com isopletia e separação entre os órgãos reprodutivos, foi caracterizada confirmando as afirmações de Taylor (1997). A isopletia está intimamente relacionada à manutenção da fecundidade da população, pois se um dos morfos se sobressai, o morfo oposto terá maior vantagem reprodutiva, devido a maior carga de pólen "oposto" estar disponível no sistema. Esta informação foi confirmada por Stehlik et al. (2006) que encontrou uma relação direta entre a densidade e a identidade do morfo circunvizinho, ao sucesso reprodutivo de determinado morfo, ou seja, quanto maior a densidade e a frequência de morfos opostos próximos a um indivíduo, maior será o fitness reprodutivo deste indivíduo. Populações de Palicourea isopléticas já foram relatadas (Machado et al. 2010; Consolaro et al. 2009), mas também variações dentro de populações distílicas já foram citadas, como em P. coriaceae (Consolaro et al. 2009), e até mesmo populações homostílicas (Coelho \& Barbosa 2003).

\section{Hercogamia}

Com relação a hercogamia recíproca, existe muita discussão sobre a real importância da reciprocidade para o fluxo simétrico de pólen, sendo um dos temas mais estudados em heterostilia nos últimos anos (Sánchez et al. 2013; Ferrero et al. 2011; Keller et al. 2012). Alguns autores acreditam que a ausência de uma reciprocidade perfeita entre as peças reprodutivas, não inviabiliza o fluxo simétrico de pólen (Faivre \& McDade 2001; Castro \& Araújo 2004; Teixeira \& Machado 2004; Consolaro 2008; Sampson \& Krebs 2012) enquanto outros demonstram que variações nos graus de hercogamia alteram a deposição de pólen entre os morfos, sendo que quanto menor a distância entre as peças reprodutivas recíprocas, maior a deposição de pólen legítimo (Guzmán et al. 2012; Baena-Díaz et al. 2012; Thompson et al. 2012; Bramow et al. 2012). Na espécie estudada percebe-se, em ambos os testes realizados para avaliar a reciprocidade, uma alta hercogamia recíproca, principalmente entre os órgãos baixos, que pode facilitar o fluxo simétrico de pólen, resultado similar descrito para outras espécies de Rubiaceae (Consolaro 2008; Coelho 2013).
As variações nos níveis de hercogamia entre os morfos não afetaram a formação de frutos em polinizações naturais em $P$. crocea, isso pode ter uma relação direta com a grande gama de visitantes que a espécie recebe, tanto de língua longa, quanto de língua curta, o que pode favorecer um fluxo simétrico mesmo não sendo perfeita a reciprocidade, similar a dados descritos em outros trabalhos (Consolaro 2008).

\section{Sistema reprodutivo}

e incompatibilidade

Os experimentos de polinização manual indicam que a espécie é xenógama, apresentando Sistema de incompatibilidade auto e intramorfo, observados através da formação de frutos e também pelo crescimento de tubos polínicos em pistilos polinizados manualmente. Resultados semelhantes, como baixa formação de frutos em autopolinização e polinização cruzada ilegítima, como encontrado para a espécie estudada, foram encontrados para outras espécies de Rubiaceae (Sobrevila et al. 1983; Barrett \& Shore 1987; Passos \& Sazima 1995; Consolaro 2008; Coelho 2013). Estes autores sugerem que o sistema de incompatibilidade nestas espécies não é muito rigoroso, podendo futuramente causar quebras da distilia e a formação de populações com desvios da distilia, como encontrado em diversas espécies de Psychotria (Consolaro 2008; Oliveira 2008; Consolaro et al. 2011; Rodrigues \& Consolaro 2013).

Variações de níveis de incompatibilidade entre os morfos também são comuns. Wedderburn \& Richards (1990) encontraram uma taxa de autocompatibilidade em Primula veris de 14,5\% em flores longistílicas e de $0,6 \%$ em flores brevistílicas, demostrando as variações dentro de sistemas de incompatibilidade, o que não foi observado para $P$. crocea.

A transferência de pólen de anteras de longos filetes para estigmas de longos estiletes é favorecida devido à facilidade no contato por uma gama muito grande de visitantes, enquanto o contrário é dificultado muitas vezes pela morfologia floral (Pailler \& Thompson 1997). Desta maneira, flores longistilas podem ter sua fecundidade aumentada. Porém este fato não foi observado em $P$. crocea, visto que a formação de frutos foi maior no morfo brevistílico em todos os tratamentos, mesmo não apresentando significância. Isso pode indicar fluxo simétrico de pólen, demonstrando eficiência dos visitantes 
florais. Dados similares já foram descritas para outras espécies (Consolaro 2008; Oliveira 2008; Valois-Cuesta et al. 2011).

\section{Visitantes florais e avaliação de néctar}

Além dos beija-flores, principais visitantes, foram registrados lepidópteros (mariposas e borboletas) e abelhas, demonstrando que a espécie, mesmo apresentando um tubo floral (cerca de $13 \mathrm{~mm}$ ), não apresenta um mecanismo eficiente de restrição às visitas, o que pode causar um grande desperdício de pólen, pois muitos visitantes são infrequentes e não fiéis, visitando outras espécies, simultaneamente, como o caso de Aellopos titan Cramer - Lepidoptera - Sphingidae e E. nigrita Lepeletier (Hymenoptera, Apidae, Euglossini), dois dos principais visitantes em $P$. crocea. Além disso, várias espécies, como Trigona spp. (Hymenoptera, Apidae) são pilhadoras e roubam néctar com perfurações na base da corola, informação já observada para outras espécies de Palicourea (Coelho \& Barbosa 2003). A produção de néctar e os padrões de coloração, além das observações focais, reforçam as definições do gênero como sendo predominantemente ornitófilo (Taylor 1997; Sobrevila et al. 1983; Coelho \& Barbosa 2003; Consolaro et al. 2009; Machado et al. 2010; Valois-Cuesta et al. 2011, 2012).

A produção de néctar similar entre os morfos florais de espécies distílicas, como o encontrado para $P$. crocea já foi descrito para outras espécies de Rubiaceae (Teixeira \& Machado 2004; Castro \& Araujo 2004; Coelho \& Barbosa 2004; Fonseca et al. 2008) e amenizam as chances de diferenças nas taxas de visitação quando a produção é diferente entre os morfos, favorecendo nesse caso, a xenogamia (Opler 1983; Proctor et al. 1996).

\section{Agradecimentos}

Ao Dr. Pietro Delprete, a identificação da espécie vegetal; à Dra. Solange Cristina Augusta, a identificação das abelhas; ao programa de Pósgraduação em Ecologia e Conservação de Recursos Naturais da Universidade Federal de Uberlândia, o auxílio.

\section{Referências}

Baena-Diáz F, Fornoni J, Sosensk P, Molina-Freaner FE, Weller SG, Pérez-Ishiwara R \& Dominguéz CA (2012) Changes in reciprocal herkogamy during the tristyly-distyly transition in Oxalis alpina increase efficiency in pollen transfer. Journal of evolutionary biology 25: 574-583.

Barrett SCH (2000) Advanced plant sex. Review of gender \& sexual dimorphism in flowering plants by Geber MA, Dawson TE \& Delph LF. Trends in Ecology \& Evolution 15: 78-79.

Barrett SCH (2010) Darwin's legacy: the forms, function and sexual diversity of flowers. Philosophical transactions of the Royal Society B, Biological Scienses 365: 351-368.

Barrett SCH \& Richards JH (1990) Heterostyly in Tropical plants. Memoirs of The New York Botanical Garden 55: 35-61.

Barrett SCH \& Shore JS (2008) New insights on heterostyly: comparative biology, ecology and genetics. In: Franklin-Tong VE (ed.) Selfincompatibility in flowering plants: evolution, diversity, and mechanisms. Springer-Verlag, Berlin. Pp. 3-32.

Bawa KS \& Beach JH (1983) Self-incompatibility systems in the Rubiaceae of a tropical lowland wet forest. American journal of botany 70: 1281-1288.

Bramow C, Hartvig I, Larsen SB \& Philipp M (2012) How a heterostylous plant species responds to life on remote islands: a comparative study of the morphology and reproductive biology of Waltheria ovata on the coasts of Ecuador and the Galápagos Islands. Evolutionary Ecology: 1-18.

Bullock SH (1985) Breeding systems in the flora of a tropical decidous forest. Biotropica 17: 287-301.

Buzato S, Sazima M \& Sazima I (2000) Hummingbirdpollinated floras in three Atlantic Forest sites. Biotropica 32: 824-841.

Castro CC \& Oliveira PEAM (2001) Reproductive biology of the protandrous Ferdinandusa speciosa Pohl (Rubiaceae) in southeastern Brazil. Revista Brasileira de Botânica 24: 167-172.

Castro CC \& Araújo AC (2004) Distyly and sequential pollinators of Psychotria nuda (Rubiaceae) in the Atlantic rain forest, Brazil. Plant Systematics and Evolution 244: 131-139.

Coelho CP (2013) Sistema reprodutivo, distilia e graus de reciprocidade em Rubiaceae arbustivas do subbosque de formações florestais do Cerrado. Tese de Doutorado. Universidade Federal de Uberlândia, Uberlândia. 161p.

Coelho CP \& Barbosa AA (2003) Biologia reprodutiva de Palicourea macrobotrys Ruiz \& Pavon (Rubiaceae): um possível caso de homostilia no gênero Palicourea Aubl. Revista Brasileira de Botânica 26: 403-413.

Coelho CP \& Barbosa AA (2004) Biologia reprodutiva de Psychotria poeppigiana Mull. Arg. (Rubiaceae), em mata de galeria. Acta Botanica Brasilica 18: 81-489.

Consolaro H, Silva EB \& Oliveira PE (2005) Variação floral e biologia reprodutiva de Manettia cordifolia Mart. (Rubiaceae). Revista Brasileira de Botânica 28: $85-94$. 
Consolaro H (2008) A distilia em espécies de Rubiaceae do bioma cerrado. Tese de Doutorado. Universidade de Brasília, Brasília. 115p.

Consolaro H, Toledo RDP, Ferreguti RL, Hay J \& Oliveira PE (2009) Distilia e homostilia em espécies de Palicourea Aubl. (Rubiaceae) do Cerrado do Brasil Central. Revista Brasileira de Botânica 32: 677-689.

Consolaro H, Silva SCS \& Oliveira PE (2011) Breakdown of distyly and pin-monomorphism in Psychotria carthagenensis Jacq. (Rubiaceae). Plant Species Biology 26: 24-320.

Contreras PS \& Ornelas JF (1999) Reproductive conflicts of Palicourea padifolia (Rubiaceae) a distylous shrub of a Tropical cloud forest in Mexico. Plant Systematics and Evolution 219: 225-241.

Dafni A, Kevan PG \& Husband BC (2005) Practical pollination biology. Enviroquest, Ltd., Cambridge, Ontario. 590p.

Darwin CR (1877) The different forms of flowers on plants of the same species. John Murray, London. $352 p$.

Dulberger R (1992) Floral polymorphisms and their functional significance in the heterostylous syndrome. In: Barrett SCH (ed.) Evolution and function of heterostyly. Monographs on theorical and applied genetics. Springer-Verlag, Berlin. Pp. 41-84.

Faegri K \& Pijl L (1979) The principles of pollination ecology. Pergamon Press, London. 529p.

Faivre AM \& McDade LA (2001) Population-level variation in the expression of heterostyly in three species of Rubiaceae: does reciprocal placement of anthers and stigmas carachterize heterostyly? American Journal of Botany 88: 841-853.

Faria RR \& Araújo AA (2016) Flowering phenology and floral visitors in distylous populations of Psychotria carthagenensis (Rubiaceae) in Brazilian Cerrado. Annals of the Missouri Botanical Garden 101: 636- 647.

Ferrero V, Arroyo J, Castro S \& Navarro L (2011) Unusual heterostyly: style dimorphism and self-incompatibility are not tightly associated in Lithodora and Glandora (Boraginaceae). Annals of botany 109: 655-65.

Fonseca LCN, Almeida EMDE \& Alves MAS (2008) Fenologia, morfologia floral e visitantes de Psychotria brachypoda (Müll. Arg.) Britton (Rubiaceae) em uma área de Floresta Atlântica, Sudeste do Brasil. Acta Botanica Brasilica 22: 63-69.

Fournier LA (1974) Un método cuantitativo para la medición de características fenológicas en árboles. Turrialba 24: 422-423.

Ganders FR (1979) The biology of heterostyly. New Zealand Journal of Botany 17: 607-635.

Gentry HA (1974) Flowering phenology and diversity in tropical Bignoniaceae. Biotropica 6: 64-68.
Guzmán IM, Lara C \& Castillo-Guevara C (2012) Transporte diferencial de polen por colibríes en una planta diestílica: no es lo mismo picos cortos que largos. Huitzil 13: 74-82.

Hernández A \& Ornelas JF (2007) Disassortative pollen transfer in distylous Palicourea padifolia (Rubiaceae), a hummingbird-pollinated shrub. EcoScience 14: 8-16.

Kearns CA \& Inouye DW (1993) Techniques for pollination biologists. University Press of Colorado, Colorado. 583p.

Keller B, De Vos JM \& Conti E (2012) Decrease of sexual organ reciprocity between heterostylous primrose species, with possible functional and evolutionary implications. Annals of botany: 1-12.

Köppen W (1958) Klimate der Erde. Wall-map 150 cm x $200 \mathrm{~cm}$. Verlag Justus Perthes, Gotha. 423p.

Kress WJ \& Beach JH (1994) Flowering plant reproductive systems. In: MacDdade LA, Bawa KS, Hespenheide HA \& Hartshorn GS (eds.) La selva - ecology and natural history of a neotropical rain forest. University of Chicago Press, Chicago. Pp. 161-182.

Lloyd DG \& Webb CJ (1986) The avoidance of interference between the presentation of pollen and stigmas in angiosperms. I. Dichogamy. New Zealand Journal of Botany 24: 135-162.

Lloyd DG, Webb CJ \& Dulberger R (1990) Heretostyly in species of Narcissus (Amaryllidaceae) and Hugonia (Linaceae) and other disputed cases. Plant Systematics and Evolution 172: 215-227.

Machado AO, Silva AP, Consolaro H, Barros MAG \& Oliveira PE (2010) Breeding biology and distyly in Palicourea rigida H.B. \& K. (Rubiaceae) in the Cerrados of Central Brazil. Acta Botanica Brasilica 24: 686-696.

Martin FW (1959). Staining and observing pollen tubes by means of fluorescence. Stain Technology 34 : 125-128.

Matias R, Oliveira AS, Furtado MT, Sá T, Rodrigues EB, Oliveira PE \& Consolaro H (2016) Sistema reprodutivo atípico de duas espécies de Rubiaceae: distilia com autoincompatibilidade parcial no morfo brevistilo? Rodriguésia 67: 357-368.

Mendonça LB \& Anjos L (2006) Flower morphology, nectar features, and hummingbird visitation to Palicourea crocea (Rubiaceae) in the Upper Paraná River floodplain, Brazil. Anais da Academia Brasileira de Ciências 78: 45-57.

Nepokroeff M, Bremer B, Sytsma KJ, Botany SS \& Mar NJ (1999) Reorganization of the genus Psychotria and tribe Psychotrieae (Rubiaceae) inferred from ITS and rbcL sequence data. Systematic Botany 24: 5-27.

Newstron LE, Frankie GW \& Baker HG (1994) A new classification for plant phenology based on flowering patterns in lowland tropical rain forest tress at $\mathrm{La}$ Selva, Costa Rica. Biotropica 26: 141-159. 
Oliveira AS (2008) Biologia reprodutiva de Psychotria L. (Rubiaceae) em floresta estacional semidecidual no sudeste brasileiro. Dissertação de Mestrado. Unicamp, Campinas. 116p.

Opler PA (1983) Nectar production in a tropical ecosystem. In: Bentley B \& Elias T (eds.) The biology of nectaries. Columbia University Press, New York. Pp. 30-79.

Pailler T \& Thompson JD (1997) Distyly and variation in heteromorphic incompatibility in Gaertnera vaginata (Rubiaceae) endemic to La Reunion Island. American journal of botany 84: 315-327.

Passos L \& Sazima M (1995) Reproductive biology of the distylous Mannetia luteo-rubra (Rubiaceae). Botanica Acta 108: 309-313.

Pérez-Barrales R (2005) La evolución de la heterostilia en Narcissus: análisis macro y microevolutivo. Tesis de Doctorado. Universidad de Sevilla. Sevilla. 326p.

Proctor M, Yeo P \& Lack A (1996) The natural history of pollination. Harper Collins, London. 479p.

Rech AR, Agostini K, Oliveira PEGM \& Machado ICS (2014) Biologia da polinização. Editora Projeto Cultural, Rio de Janeiro. 524p.

Ree RH (1997) Pollen flow, fecundity, and the adaptive significance of heterostyly in Palicourea padifolia (Rubiaceae). Biotropica 29: 298-308.

Richards JH \& Koptur S (1993) Floral Variation and distyly in Guettarda scraba (Rubiaceae). American Journal of Botany 80: 31-40.

Rodrigues EB \& Consolaro H (2013) Atypical distyly in Psychotria goyazensis Mull Arg. (Rubiaceae), an intramorph self-compatible species. Acta Botanica Brasilica 27: 155-161.

Ruiz TZ \& Arroyo MTK (1978) Plant reproductive ecology of a secondary deciduous tropical forest. Biotropica 10: 221-230.

Sampson DA \& Krebs RA (2012) Quantitative evaluation of reciprocal herkogamy in the distylous species, Hedyotis caerulea (Rubiaceae). Plant Systematics and Evolution 298: 1361-1370.

Sánchez LM, Ferrero V \& Navarro L (2013) Quantifying reciprocity in distylous and tristylous plant populations. Plant Biology 15: 616-620.

Sobrevila C, Ramirez N \& Enrech NX (1983) Reproductive biology of Palicourea fendleri and
$P$. petiolares (Rubiaceae), heteostilious shrubs of a tropical cloud forest in Venezuela. Biotropica 15: 161-169.

Stehlik I, Caspersen JP \& Barrett SCH (2006) Spatial ecology of mating success in a sexually polymorphic plant. Proceedings of the Royal Society of London, B, Biological Sciences 273: 387-394.

Tanner E (1982) Breeding systems in a tropical forest in Jamaica. Biological Journal of the Linnean Society 18: 263-278.

Taylor CM (1997) Conspectus of the genus Palicourea (Rubiaceae: Psychotriae) with the description of some new species from Ecuador and Colombia. Annals of the Missouri Botanical Garden 84: 224-262.

Teixeira LAG \& Machado IC (2004) Biologia da polinização e sistema reprodutivo de Psychotria barbiflora DC. (Rubiaceae). Acta Botanica Brasilica 18: 853-86.

Thompson JD, Cesaro AC \& Arroyo J (2012) Morph ratio variation and sex organ reciprocity in styledimorphic Narcissus assoanus. International Journal of Plant Sciences 173: 885-893.

Valois-Cuesta H, Soriano PJ \& Ornelas JF (2011) Dimorphisms and self-incompatibility in the distylous species Palicourea demissa (Rubiaceae): possible implications for its reproductive output. Journal of plant research 124: 137-46.

Valois-Cuesta H, Soriano PJ \& Ornelas JF (2012) Gender specialization in Palicourea demissa (Rubiaceae), a distylous, hummingbird-pollinated treelet. Plant Systematics and Evolution 298: 975-984.

Vuilleumier BS (1967) The origin and evolutionary development of heterostyly in the angiosperms. Evolution 21: 210-226.

Webb CJ \& Lloyd DG (1986) The avoidance of interference between the presentation of pollen and stigmas in Angiosperms II. Hercogamy. New Zealand Journal of Botany 24: 163-178.

Wedderburn F \& Richards AJ (1990) Variation in within morph incompatibility sites in heteromorphic Primula L. New Phytologist 116: 149-162.

Weller SG (2009) The different forms of flowers - what have we learned since Darwin. Botanical Journal of Linnean Society 160: 249-261. 